del hecho de ser mujeres en la Antigüedad, sino que también nos proporciona la prueba fehaciente de que otras maneras de mirar con justicia al pasado son posibles.

LORENA GARRI-CATCHOT lgarri@ub.edu

Universitat de Barcelona

\title{
Sabedoras y desvergonzadas. Ensayos de investigación para una enseñanza generizada de la historia medieval y moderna
}

Miriam Moriconi (dir.)

Rosario, HyA Ediciones-Universidad Nacional de Rosario, 2019, 221 pp. ISBN: 978-987-3638-34-3

Cuando tuve por vez primera en mis manos esta obra colectiva, lo primero que me llamó la atención fue el título: me sentí atrapada por él. Y es que su directora ha sabido elegir estas palabras, "sabedoras y desvergonzadas", cargadas de sentido, abiertas e imaginativas, tanto para los lectores como para las lectoras menos acostumbrados / acostumbradas a leer libros de historia de las mujeres como para quienes estamos trabajando algunos períodos de la misma. Porque estas dos palabras tienen esa tensión que tanto nos agrada escudriñar. Pero, además, se trata de palabras muy antiguas. El misterio de su origen, para quienes no lo recuerden, queda desvelado en la presentación y se retrotrae a las Siete Partidas del rey Alfonso X, cuyos redactores retoman un pasaje de Ulpiano a partir del cual se establecía el criterio de exclusión por razón de sexo que restringía los oficios de justicia a los varones. Redactado por M. Moriconi, el título de esta presentación, “Algunos pétalos lanzados en la tumba de Aphra Behn", que evoca a una escritora inglesa del siglo XVII, nos aclara el origen del libro y augura con su delicado estilo la agradable lectura que nos espera. En conjunto, se ofrecen cinco capítulos basados en investigaciones sobre historia medieval y moderna en perspectiva de género, desarrollados en la Universidad Nacional de Rosario (Argentina).

El objetivo primero ha sido dar impulso a una visión de la historia generizada, imbuido de tantas ansias compartidas por abandonar en la enseñanza esas versiones historiográficas androcéntricas que, a pesar de los esfuerzos allá y aquí, aún son dominantes. Pero se preguntará el lector/la lectora si esta palabra es un invento. Y así es. No existe el término "generizado-a" en los diccionarios de la Real Academia Española, y así es como su uso, su atrevimiento, nos interpela aún más a romper y a cambiar para consolidar ese objetivo. Para la autora, "generizar" es desmontar el funcionamiento del género como dispositivo de dominación, también el conjunto de agencias desigualitarias creadas por la heteronormatividad. 
Y todas las protagonistas de esta obra, conocidas o no, osaron desvergonzadamente - en palabras de Miriam Moriconi- leer, interpretar, escribir, crear, habitar espacios que les eran vedados, elegir a sus parejas más allá de las imposiciones y hasta decidir sobre sus cuerpos, pese a la inclemencia de los castigos con los que fueron amenazadas. Luchas contra las hegemonías, en suma.

Ahí vamos a encontrar el trabajo de M. Loiza titulado "Componer y crear aun en contextos adversos. La producción musical en Hildegarda Von Bingen (10981179)", que nos introduce en la interdisciplinariedad, siempre reclamada. Así pues, cómo las mujeres se han relacionado con la música es una interesante pregunta por la que nos lleva este capítulo, que nos permite ver con distintos ojos la lucha de aquella abadesa visionaria del siglo XII que resignificó el valor del sonido con el origen, lo sagrado, dando voz a personajes femeninos. Tras su contribución, la obra da paso a la Edad Moderna a través de T. Pisano, cuya aportación, titulada "El sentido del pasado en tiempos de Revolución. Sus usos en la defensa de las mujeres en cuatro escritoras inglesas del siglo XVII", da a conocer voces femeninas que a raíz de los hechos revolucionarios de 1640 clamaron ya por una apelación a la Historia. Y lo hicieron, como correspondía a aquellos tiempos, conociendo, leyendo y traduciendo los textos sagrados, una inmersión bíblica que iba a permitir el cuestionamiento de los discursos coetáneos que relegaban a la mujer a una posición subordinada. Estas mujeres fueron Rachel Speght, Katherine Chidley, Margaret Fell y Bathsua Reynolds Makin. Ellas respondieron, acusaron, argumentaron, interpelaron, demostraron capacidades, injusticias, desigualdades. El siguiente trabajo, de N. Silvestri, se titula "Experiencias de la esclavitud en una mujer colonial. Las mujeres esclavizadas frente al matrimonio en Santa Fe del Río de la Plata en el siglo XVIII". Se trata de un estudio imprescindible porque rescata a las más discriminadas de entre las discriminadas y descubre un microcosmos de decisiones, de voluntades no condicionadas, como lo fue la elección del matrimonio. Agencias, en fin, en los márgenes, aprovechando las paradojas del sistema. Sigue a este un trabajo de la coordinadora que, bajo el título "Así a las madres como a sus frutos. Saberes y prácticas sobre la gestación y el parto en manos de los curas en tiempos de la Pragmática sobre abortos y cesáreas", nos adentra en la historia del cuerpo apropiado por el discurso de los teólogos, del poder político, centrado en el asunto de la cultura de la vida intrauterina desde la muy traducida Embriología sacra, del franciscano Cangiamila, conocido en torno a 1745, y cuyos planteamientos fueron adoptados por Carlos VII de Nápoles y Sicilia en su Real Pragmática. Continúa la senda el texto de A. Milano titulado "Mujeres en discursos masculinos. Persistencia de los hombres de la Iglesia en espacios laicos de la España ilustrada del siglo XVIII", que me devuelve a mi tierra, pues analiza la implicación de quien fuera obispo de Barcelona, Josep Climent, con la traducción al castellano de las Instructions sur le mariage de Le Tourneaux, que ejecutaría la 
ilustrada condesa de Montijo. Según la autora, esta es una opción para releer la Ilustración redescubriendo textos, detectando hibridaciones y cuestionando límites, pues pese al cambio atribuido a las damas de la Sociedad Económica de Amigos del País en la formación y la participación femenina, también fueron un canal de objetivación y difusión de discursos masculinos. Finaliza el libro una acertada relación bibliográfica.

Creo, para concluir, que esta es una obra llena de interrogantes y reflexiones, que a buen seguro interesará a los alumnos-as para los-as que fue primero pensada, pero también una referencia para todos-as por su frescura y su amplitud de miras.

Mariela Fargas Peñarrocha marielafargas@ub.edu

Universitat de Barcelona

\section{Escritoras monjas. Autoridad y autoría en la escritura conventual femenina de los Siglos de Oro}

Julia Lewandowska

Madrid-Fráncfort, Iberoamericana-Vervuert, 2019, 529 pp. ISBN: 978-

84-9192-046-5

El volumen que nos ocupa es una novedosa propuesta de lectura e interpretación de textos conventuales femeninos de los Siglos de Oro españoles. Su autora, la doctora Julia Lewandowska, es profesora en la Facultad de Artes Liberales de la Universidad de Varsovia (Polonia). La obra ha merecido justamente la honrosa mención a la mejor monografía crítica de los premios Victoria Urbano 2020, otorgados por la Asociación de Estudios de Género y Sexualidades (AEGS), y ha sido acertadamente editada por Iberoamericana-Vervuert dentro de la colección de clásicos hispánicos.

La perspectiva de la autora, que integra los estudios literarios, los estudios de género y la antropología religiosa y cultural, ofrece en el volumen tres secciones interconectadas, con una introducción previa y unas conclusiones, además de un apéndice biográfico de autoras que acompaña complementariamente la lectura de las tres partes principales, que son el centro de su análisis.

La primera parte desvela la premisa que guía este volumen: el cuestionamiento de la mirada investigadora hacia los textos de las escritoras religiosas altomodernas y su resituación en sus respectivos contextos, para, a través de preguntas que interpelan las obras y sus autoras, hacer emerger las estrategias discursivas de autoridad y autoría que utilizaron para dialogar dentro del panorama cultural 